\title{
Inhibition of migration and invasion of LNCaP human prostate carcinoma cells by cordycepin through inactivation of Akt
}

\author{
JIN-WOO JEONG ${ }^{1,2}$, CHENG-YUN JIN ${ }^{3,4}$, CHEOL PARK $^{1,4}$, MIN HO HAN ${ }^{3}$, \\ GI-YOUNG KIM ${ }^{5}$, SUNG-KWON MOON ${ }^{6}$, CHAN GIL KIM $^{7}$, YONG KEE JEONG ${ }^{8}$, \\ WUN-JAE KIM ${ }^{9}$, JAE-DONG LEE ${ }^{2}$ and YUNG HYUN CHOI ${ }^{1,3,4}$
}

\begin{abstract}
${ }^{1}$ Department of Biochemistry and Research Institute of Oriental Medicine, Dongeui University College of Oriental Medicine, Busan 614-052; ${ }^{2}$ Department of Microbiology, College of Natural Sciences, Pusan National University, Busan 609-735; ${ }^{3}$ Department of Biomaterial Control (BK21 program), Dongeui University Graduate School; ${ }^{4}$ Blue-Bio Industry Regional Innovation Center, Dongeui University, Busan 614-714; ${ }^{5}$ Laboratory of Immunobiology, Department of Marine Life Sciences, Jeju National University, Jeju 690-756; ${ }^{6}$ Department of Food and Biotechnology, Chungju National University; ${ }^{7}$ Department of Biotechnology, Konkuk University, Chungju 380-701; ${ }^{8}$ Department of Biotechnology, College of Natural Resources and Life Science, Dong-A University, Busan 604-714; ${ }^{9}$ Personalized Tumor Engineering Research Center and Department of Urology, Chungbuk National University College of Medicine, Cheongju 361-763, Republic of Korea
\end{abstract}

Received October 7, 2011; Accepted December 27, 2011

DOI: $10.3892 /$ ijo.2012.1332

\begin{abstract}
Cordycepin (3'-deoxyadenosine), a major bioactive compound of Cordyceps militaris, has many pharmacological actions, such as anti-inflammatory and anticancer activities. In this study, the relationship between inhibition of cell motility and anti-invasive activity by cordycepin in LNCaP human prostate carcinoma cells was investigated. Within the concentration range that was not cytotoxic, cordycepin time-dependently inhibited cell motility and invasiveness of LNCaP cells. The inhibitory effects of cordycepin on cell invasiveness were associated with tightening of tight junctions (TJs), which was demonstrated by an increase in transepithelial electrical resistance (TER). Immunoblotting indicated that cordycepin decreases levels of claudin proteins, which are major components of TJs that play a key role in control and selectivity of paracellular transport. Furthermore, cordycepin inhibited the expression and activity of matrix metalloproteinase (MMP)-2 and MMP-9, and simultaneously increased levels of tissue inhibitor of metalloproteinase (TIMP)-1 and TIMP-2. These effects were related to inactivation of the phosphoinositide 3-kinase (PI3K)/Akt pathway in LNCaP
\end{abstract}

Correspondence to: Dr Jae-Dong Lee, Department of Microbiology, College of Natural Sciences, Pusan National University, Busan 609-735, Republic of Korea

E-mail: leejd@pusan.ac.kr

Dr Yung Hyun Choi, Department of Biochemistry, Dongeui University College of Oriental Medicine, Busan 614-052, Republic of Korea

E-mail: choiyh@deu.ac.kr

Key words: cordycepin, invasion, tight junctions, matrix metalloproteinases, PI3K/Akt cells. These findings suggest that cordycepin inhibits the migration and invasion of LNCaP cells by downregulating the activity of TJs and MMPs, possibly in association with suppression of Akt activation.

\section{Introduction}

Metastasis is a process by which cancer spreads from the place at which it first arose as a primary tumor to distant locations in the body. The process involves several steps: invasion of adjacent tissues, intravasation, transport of cancer cells through the circulatory system, arrest at a secondary site, extravasation, and growth in a secondary organ. In epithelial cells, several specialized and distinct intercellular structures, including the gap junction, tight junction (TJ), adherens junction (AJ), and desmosome, are responsible for establishment of contact between neighboring cells. Among these, TJs, situated at the membrane between apical and lateral regions of polarised epithelial cells, selectively regulate the passage of molecules and ions via the paracellular pathway, and also restrict the lateral movement of molecules in the cell membrane $(1,2)$. In precancerous lesions of the epithelia and cancerous epithelia, TJ strands become disorganized or lost altogether and TJs become 'leaky', as indicated by decreased resistance to electrical current (measured by transepithelial electrical resistance; TER) and increased markers of paracellular permeability $(1,3,4)$. Claudins, which are major integral membrane proteins that form the backbone of TJs, can form homodimers or heterodimers to produce paired strands between adjacent cells and act as a barrier to the paracellular flux of water, solution and transmigration of other cells, thereby determining the characteristic permeability properties of different epithelial tissues (5-7). Recent studies have provided evidence that claudins are aberrantly expressed in various cancers and are associated 
with development and progression of cancer, which suggests that they have key cellular functions that are distinct from their roles in TJ-complexes (8-10).

The matrix metalloproteinases (MMPs), a family of zinc-dependent endopeptidases, play an important role in inflammatory tissue destruction, angiogenesis, and cancer cell metastasis. In cancer cells, these enzymes may contribute to cell invasion favoring modifications to the matrix, resulting in tumor cell invasion $(11,12)$. Invasive cancer cells utilize MMPs to degrade the extracellular matrix (ECM) and basement membrane during metastasis. Among the human MMPs reported to date, the enzymes gelatinases A (MMP-2) and B (MMP-9), which are expressed abundantly in various malignant tumors, contribute to cancer invasion and metastasis. Generally, MMP-2 $(72 \mathrm{kDa})$ is preferentially secreted from fibroblasts and various epithelial cells, while MMP-9 $(92 \mathrm{kDa})$ is preferentially expressed by inflammatory cells, and both have been frequently associated with the invasive metastatic potential of tumor cells $(13,14)$. The so-called tissue inhibitors of metalloproteinases (TIMPs), which are naturally occurring inhibitors of MMPs, play an important role in the complex regulation of MMPs. They inhibit the catalytic activity of MMPs by binding to activated MMPs and control breakdown of ECM $(15,16)$. Thus, the balance between MMPs and TIMPs plays a vital role in maintaining the integrity of healthy tissues, and MMP inhibitors, as well as TIMP activators, are expected to be useful chemotherapeutic agents for the treatment of malignancies.

Cordycepin (3'-deoxyadenosine), a derivative of the nucleoside adenosine, is a major functional component in the Cordyceps militaris fungus $(17,18)$, which belongs to the class Ascomycetes and has been widely used for a long time in traditional Chinese medicine. Due to the absence of oxygen in the 3 ' position of its ribose moiety, the incorporation of cordycepin during RNA synthesis results in termination of chain elongation. This activity has been well described in vitro with purified RNA polymerases and poly(A) polymerases from a number of organisms, including yeast and mammals $(19,20)$. Although the roles and mechanisms of cordycepin as a potential chemotherapeutic agent have not been completely elucidated, several recent studies have indicated that cordycepin inhibits growth of cancer cells and induces apoptotic cell death (21-25). However, the molecular mechanisms underlying the anti-metastatic effects of cordycepin are not yet completely understood.

Therefore, in this study, we attempted to elucidate the antimetastatic potential of cordycepin using an LNCaP human prostate carcinoma cell line and the underlying intracellular signal transduction pathways involved in inhibition of metastasis. Results of this study demonstrated that cordycepin inhibits two aspects of metastatic potential, cell motility and invasiveness, through modulation of the levels of TJ-associated factors and the activities of MMPs.

\section{Materials and methods}

Cell culture and MTT assay. LNCaP human prostate carcinoma cells were obtained from the American Type Culture Collection (Rockville, MD, USA) and cultured in RPMI-1640 supplemented with $10 \%$ fetal bovine serum (FBS) (Gibco BRL, Gaithersburg, MD, USA) and $1 \%$ penicillin-streptomycin at $37^{\circ} \mathrm{C}$ in a humidified $95 \%$ air and $5 \% \mathrm{CO}_{2}$. Cordycepin (SigmaAldrich Chemical Co., St Louis, MO, USA) was dissolved in distilled water as a stock solution at a $1 \mathrm{mg} / \mathrm{ml}$ concentration and was stored in aliquots at $-20^{\circ} \mathrm{C}$. For the cell viability study, $\mathrm{LNCaP}$ cells were grown to $70 \%$ confluence and treated with cordycepin. Following treatment, cell viability was determined by 3-(4,5-dimethyl-2 thiazolyl)-2,5-diphnyl-2H-tetrazolium bromide (MTT) (Sigma-Aldrich) assay, which is based on conversion of MTT to MTT-formazan by mitochondria.

Wound healing migration assay. LNCaP cells were grown to confluence on 30-mm cell culture dishes coated with $20 \mu \mathrm{g} /$ $\mathrm{ml}$ of rat tail collagen (BD Biosciences, Bedford, MA, USA). Confluent cells were wounded by scraping with a pipette tip. After wounding, cultures were washed twice with PBS and control cells were exposed to medium alone. The cells were incubated with $1 \%$ FBS-containing medium supplemented with various concentrations of cordycepin for $48 \mathrm{~h}$. Wound closure of cells was observed and photographed under the microscope at $\mathrm{x} 40$ magnification. The culture treatments were repeated twice and each sample was assayed in triplicate (26).

Measurement of TER. TER (a measure of tight junction formation) was measured with an EVOM Epithelial Tissue Voltohmmeter (World Precision Instruments, FL, USA), equipped with a pair of STX-2 chopstick electrodes. Briefly, NLCaP cells were seeded into the $8.0 \mu \mathrm{m}$ pore size insert (upper chamber) of a Transwell ${ }^{\circledR}$ (Corning Costar Corp., NY, USA) and allowed to reach full confluence, after which fresh medium was replaced for further experiments. Inserts without cells, inserts with cells in medium, and inserts with cells with cordycepin were treated for $48 \mathrm{~h}$. Electrodes were placed at the upper and lower chambers, and resistance was measured with the voltohmmeter (27).

In vitro invasiveness assay. Matrigel invasion assays were used for assessment of the ability of LNCaP cells to penetrate ECM in the presence or absence of cordycepin. Briefly, cells were exposed to 5 or $10 \mu \mathrm{g} / \mathrm{ml}$ of cordycepin for $6 \mathrm{~h}$, and treated cells $(50,000)$ were then plated onto the apical side of Matrigelcoated filters in serum-free medium containing 5 or $10 \mu \mathrm{g} / \mathrm{ml}$ of cordycepin. Medium containing 20\% FBS was placed in the basolateral chamber to function as a chemoattractant. After $48 \mathrm{~h}$, cells on the apical side were wiped off with a Q-tip. Cells on the bottom of the filter were stained with hematoxylin and eosin Y (Sigma) and counted (three fields of each triplicate filter) using an inverted microscope.

$R N A$ extraction and reverse transcription-PCR. Total RNA was prepared using an RNeasy kit (Qiagen, La Jolla, CA, USA) and primed with random hexamers for synthesis of complementary DNA using AMV reverse transcriptase (Amersham Corp., Arlington Heights, IL, USA), according to the manufacturer's instructions using DNAse I (1 U/ $/ \mu \mathrm{g}$ RNA) pretreated total mRNA. Polymerase chain reaction (PCR) was carried out in a Mastercycler (Eppendorf, Hamburg, Germany) using the primers indicated in Table I. Conditions for PCR reactions were $1 \mathrm{x}\left(94^{\circ} \mathrm{C}\right.$ for $\left.3 \mathrm{~min}\right), 35 \mathrm{x}\left(94^{\circ} \mathrm{C}\right.$ for $45 \mathrm{sec} ; 58^{\circ} \mathrm{C}$ for $45 \mathrm{sec}$; and $72^{\circ} \mathrm{C}$ for $\left.1 \mathrm{~min}\right)$, and $1 \mathrm{x}\left(72^{\circ} \mathrm{C}\right.$ for $\left.10 \mathrm{~min}\right)$. Amplification products obtained by PCR were electrophoretically separated 
Table I. Sequences of the primer pairs employed in the RT-PCR reactions.

\begin{tabular}{ll}
\hline Name & \multicolumn{1}{c}{ Sequence of primers } \\
\hline TIMP-1 & \\
Sense & 5'-TGG-GGA-CAC-CAG-AAG-TCA-AC-3' \\
Antisense & 5'-TTT-TCA-GAG-CCT-TGG-AGG-AG-3' \\
TIMP-2 & \\
Sense & 5'-GTC-AGT-GAG-AAG-GAA-GTG-GAC-TCT-3' \\
Antisense & 5'-ATG-TTC-TTC-TCT-GTG-ACC-CAG-TC-3' \\
MMP-9 & \\
Sense & 5'-CGG-AGC-ACG-GAG-ACG-GGT-AT-3' \\
Antisense & 5'-TGA-AGG-GGA-AGA-CGC-ACA-GC-3' \\
Claudin-2 & \\
Sense & 5'-ACA-CAC-AGC-ACA-GGC-ATC-AC-3' \\
Antisense & 5'-TCT-CCA-ATC-TCA-AAT-TTC-ATG-C-3' \\
Claudin-3 & \\
Sense & 5'-AAG-GCC-AAG-ATC-ACC-ATC-GTG-3' \\
Antisense & 5'-AGA-CGT-AGT-CCT-TGC-GGT-CGT-3' \\
Claudin-4 & \\
Sense & 5'-TGG-ATG-AAC-TGC-GTG-GTG-CAG-3' \\
Antisense & 5'-GAG-GCG-GCC-CAG-CCG-ACG-TA-3' \\
Claudin-5 & \\
Sense & 5'-GCC-ATG-GGG-TCC-GCA-GCG-TT-3' \\
Antisense & 5'-AGT-CTG-CAT-CAA-GAA-GA-3' \\
GAPDH & \\
Sense & 5'-CGG-AGT-CAA-CGG-ATT-TGG-TCG-TAT-3' \\
Antisense & 5'-AGC-CTT-CTC-CAT-GGT-GGT-GAA-GAC-3' \\
\hline
\end{tabular}

on $1 \%$ agarose gel and visualized by ethidium bromide (EtBr) staining.

Protein extraction and western blot analysis. Total cell lysates were prepared in an extraction buffer $[25 \mathrm{mM}$ Tris- $\mathrm{Cl}(\mathrm{pH} 7.5)$, $250 \mathrm{mM} \mathrm{NaCl}, 5 \mathrm{mM}$ ethylendiaminetetra acetic acid, $1 \%$ nonidet $\mathrm{P}-40,0.1 \mathrm{mM}$ sodium orthovanadate, $2 \mu \mathrm{g} / \mathrm{ml}$ leupeptin, and $100 \mu \mathrm{g} / \mathrm{ml}$ phenylmethylsulfonyl fluoride]. Protein concentration was determined using a Bio-Rad protein assay kit (Bio-Rad, Laboratories, Hercules, CA, USA). For western blot analysis, proteins (30-50 $\mu \mathrm{g})$ were separated by $8-10 \%$ sodium dodecyl sulfate (SDS)-polyacrylamide gel electrophoresis and then electrotransferred to a nitrocellulose membrane (Schleicher \& Schuell, Keene, NH, USA). Membranes were blocked with $5 \%$ skim milk for $1 \mathrm{~h}$, and were then subjected to immunoblot analysis using the desired antibodies. Proteins were then visualized by the enhanced chemiluminescence (ECL) method, according to the recommended procedure (Amersham Co.). Primary antibodies were purchased from Santa Cruz Biotechnology Inc. (Santa Cruz, CA, USA) and Calbiochem (Cambridge, MA, USA). Peroxidase-labeled donkey anti-rabbit immunoglobulin and peroxidase-labeled sheep anti-mouse immunoglobulin were obtained (Amersham Co.).
Gelatin zymographic analysis of secreted MMPs. Following incubation with cordycepin for $48 \mathrm{~h}$, cell culture supernatants were collected and centrifuged at $400 \mathrm{x} \mathrm{g}$ for $5 \mathrm{~min}$. Cell-free supernatant was mixed with $2 \mathrm{X}$ sample buffer (Invitrogen) and zymography was performed using precast gels $(10 \%$ polyacrylamide and $0.1 \%$ gelatin). Following electrophoresis, gels were washed twice at room temperature for $30 \mathrm{~min}$ in $2.5 \%$ Triton $\mathrm{X}-100$, subsequently washed in buffer containing $50 \mathrm{mM}$ Tris- $\mathrm{HCl}, 150 \mathrm{mM} \mathrm{NaCl}, 5 \mathrm{mM} \mathrm{CaCl}_{2}, 1 \mu \mathrm{M} \mathrm{ZnCl}_{2}$, and $0.02 \% \mathrm{NaN}_{3}$ at $\mathrm{pH} 7.5$ and incubated in this buffer at $37^{\circ} \mathrm{C}$ for $24 \mathrm{~h}$. Thereafter, gels were stained with $0.5 \%(\mathrm{w} / \mathrm{v})$ Coomassie brilliant blue G-250 (Bio-Rad) for $1 \mathrm{~h}$, then lightly destained in methanol/acetic acid/water (3:1:6). Clear bands appear on the Coomassie stained blue background in areas of gelatinolytic activity. Gels were scanned and images were processed by extraction of the blue channel signal, converting it to black and white, and inverting it for quantification of gelatinolytic activities from the integrated optical density (28).

Statistical analysis. All data are presented as mean \pm S.D. Significant differences among the groups were determined using the unpaired Student's t-test. A value of $p<0.05$ was accepted as an indication of statistical significance. All of the figures shown herein were obtained from at least three independent experiments.

\section{Results}

Cordycepin inhibits cell growth and migration of LNCaP cells. In order to investigate the effect of cordycepin on the viability of LNCaP cells, cells were treated with various concentrations of cordycepin for $48 \mathrm{~h}$ and subjected to MTT assay. When compared with the control, treatment with $20 \mu \mathrm{g} / \mathrm{ml}$ cordycepin caused approximately $49 \%$ inhibition of cell growth. However, cordycepin in the range of 2-10 $\mu \mathrm{g} /$ $\mathrm{ml}$ did not have a significant cytotoxic effect on LNCaP cells (Fig. 1A). Therefore, a concentration of cordycepin within this lower range was used in the remaining experiments. To investigate the inhibitory effect of cordycepin on migration of LNCaP cells, an in vitro wound healing assay was performed. Results demonstrated that $10 \mu \mathrm{g} / \mathrm{ml}$ cordycepin, which was not cytotoxic, as shown by MTT assay, time-dependently delayed the motility of LNCaP cells compared to that of control cells (Fig. 1B).

Cordycepin increased TER values and decreased cell invasion by LNCaP cells. To examine the relationship between function of TJs and the anti-invasive activity of LNCaP cells treated with cordycepin, TER values were measured. As shown in Fig. 2A incubation of cells with cordycepin substantially increased their TER levels in a dose-dependent manner, suggesting that cordycepin increases tightening of TJs in LNCaP cells. Using a Boyden chamber invasion assay, we next attempted to determine whether the inhibitory effects of cordycepin were connected to the decreases in cell invasion. As shown in Fig. 2B and C, cordycepin treatment resulted in markedly reduced cell invasion through the Matrigel chamber in a concentration-dependent manner, suggesting that the inhibitory effects of cell migration are associated with inhibition of invasive activity in $\mathrm{LNCaP}$ cells. 
A)

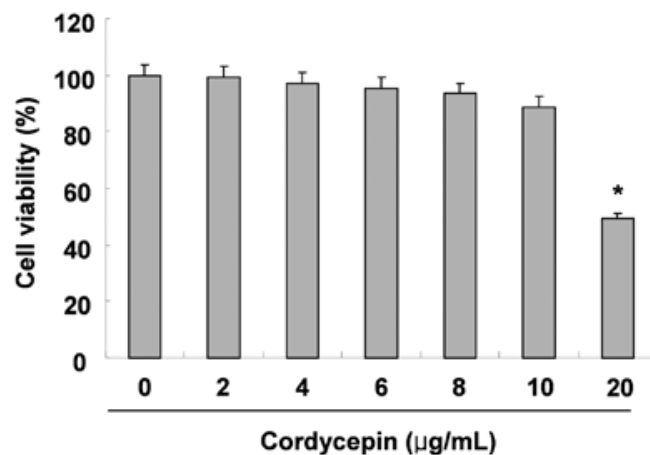

B)

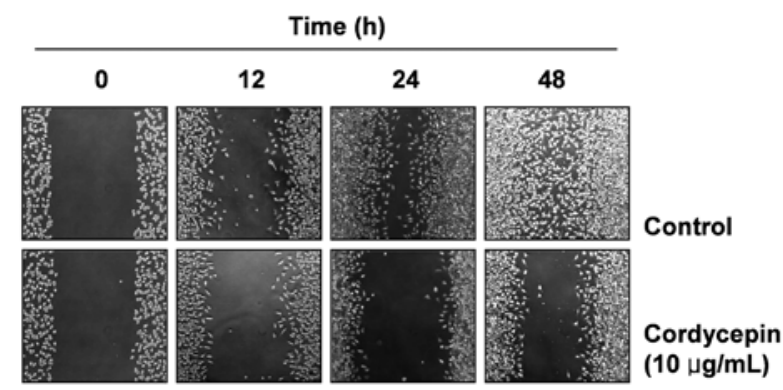

Figure 1. Effects of cordycepin on cell viability and motility in LNCaP cells (A) Cells were seeded at an initial density of $2.5 \times 10^{5}$ cells per $60-\mathrm{mm}$ plate, incubated for $24 \mathrm{~h}$, and treated with various concentrations of cordycepin for $48 \mathrm{~h}$. Cell viability was measured using an MTT assay. Each point represents the mean \pm SD of three independent experiments. A Student's t-test was used for determination of significance ( $" \mathrm{p}<0.05$ vs. untreated control). (B) Cells were grown to confluency on 30-mm cell culture dishes; a scratch was then made through the cell layer using a pipette tip. After washing with PBS, serum free media (to prevent cell proliferation) containing either vehicle or cordycepin $(10 \mu \mathrm{g} / \mathrm{ml})$ was added for the indicated times. Images of the wounded area were taken for evaluation of cell movement into the wounded area

Cordycepin modulated the expression levels of TJ-related proteins in LNCaP cells. To elucidate the mechanism by which cordycepin enhances TJ activity and reduces invasive activity, we determined the levels of TJs and adherens junction (AJ) components, as well as TJ regulators such as claudins (claudin-2, $-3,-4$ and -5), E-cadherin and Snail, using RT-PCR and western blot analysis. As shown in Fig. 3, the levels of claudins (claudin-2, $-3,-4$ and -5 ), the most important components of the TJ, were dose-dependently downregulated in cordycepin-treated cells at the transcriptional and translational levels, suggesting that this modulation contributes to TJ tightening. In addition, the levels of snail, an EMT regulator and zinc finger transcription factor $(29,30)$, were markedly inhibited by cordycepin treatment. However, those of E-cadherin, a type I transmembrane glycoprotein that regulates $\mathrm{TJ}$ and $\mathrm{AJ}$ formation $(31,32)$, remained unchanged.

Cordycepin inhibits activation and expression of MMPs in LNCaP cells. Since activating MMPs is crucial for ECM degradation, which is required for metastasis $(11,12)$, we tested the effects of cordycepin on activation and expression of MMPs using gelatin zymography, RT-PCR and western blot analyses. Data indicated that activities of MMP-2 and -9 in LNCaP cells were significantly decreased by cordycepin treatment, which was connected with a concurrent downregulation of their
A)

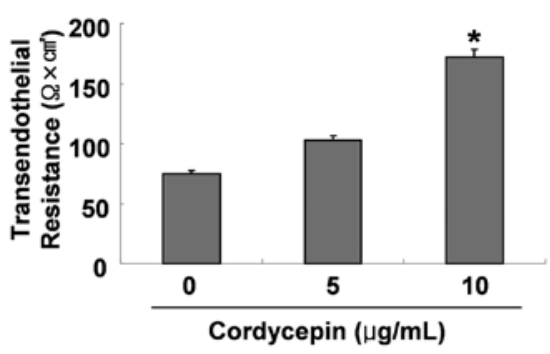

B)

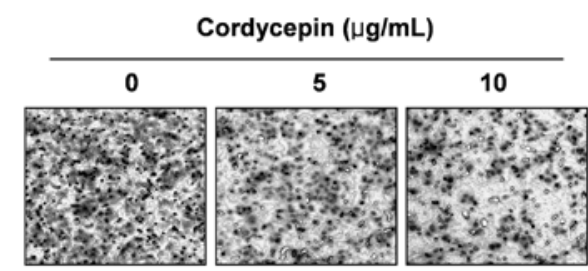

C)

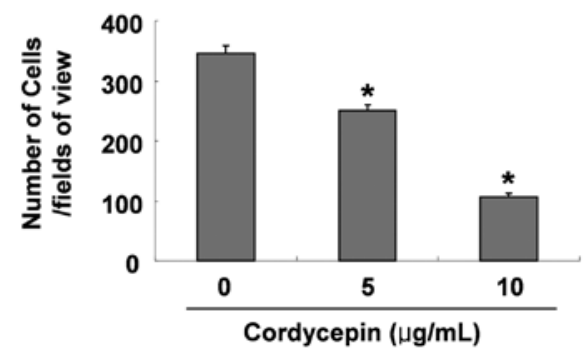

Figure 2. Increase of TER values and decrease of cell invasion by cordycepin in LNCaP cells. (A) Cells were treated with 5 or $10 \mu \mathrm{g} / \mathrm{ml}$ of cordycepin for $48 \mathrm{~h}$, and TER values were measured using an EVOM Epithelial Tissue Voltohmmeter, as described in the Materials and methods. Results are shown as the mean $\pm \mathrm{SD}$ of three independent experiments. A Student's t-test was used for determination of significance ( $\mathrm{p}<0.05$ versus untreated control). (B and C) Cells pretreated with 5 or $10 \mu \mathrm{g} / \mathrm{ml}$ of cordycepin for $6 \mathrm{~h}$ were plated onto the apical side of matrigel coated filters in serum-free medium containing either vehicle or cordycepin. Medium containing 20\% FBS was placed in the basolateral chamber to act as a chemoattractant. After $48 \mathrm{~h}$, cells on the apical side were wiped off using a Q-tip. Next, cells on the bottom of the filter were stained using hematoxylin and eosin $\mathrm{Y}(\mathrm{B})$, and then counted (C). Data are shown as the mean of triplicate samples and represent invasive cell numbers compared with those of control cells. ${ }^{*} p<0.05$ versus untreated control.

mRNA and protein levels (Fig. 4). However, cordycepin treatment markedly increased TIMP-1 and -2 mRNA and protein levels in a concentration-dependent manner. These results indicate that the anti-invasive effect of cordycepin is associated with increased TIMP levels, as well as inhibition of MMP-2 and -9 mRNA, protein expression, and activity in LNCaP cells.

Increase in cordycepin-induced anti-invasiveness by inhibition of the PI3K/Akt signal pathway. Several lines of evidence have implicated phosphoinositide 3-kinase (PI3K)/Akt in regulating MMPs and TJs, which have been implicated in a number of cellular functions including cell survival, adhesion and metastasis $(33,34)$. Therefore, the effects of cordycepin on the phosphorylation status of Akt in LNCaP cells were investigated. Data demonstrated that cordycepin treatment markedly decreases the phosphorylation of Akt in a concentration-dependent manner (Fig. 5A). We then evaluated the possible role of PI3K/Akt signaling in cordycepin-induced anti-invasive activity. As shown in Fig. 5B-D, cordycepin-mediated downregulation of MMP 
A)

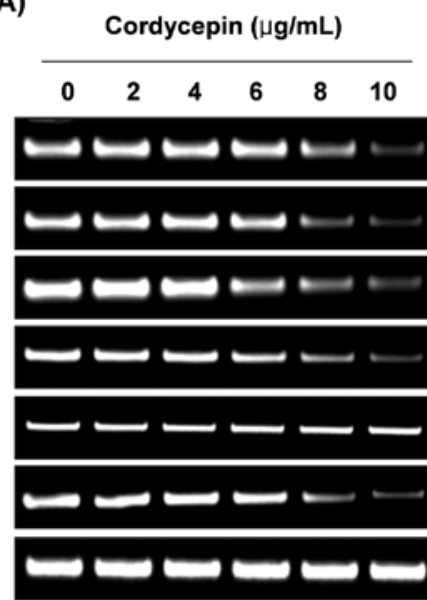

B)

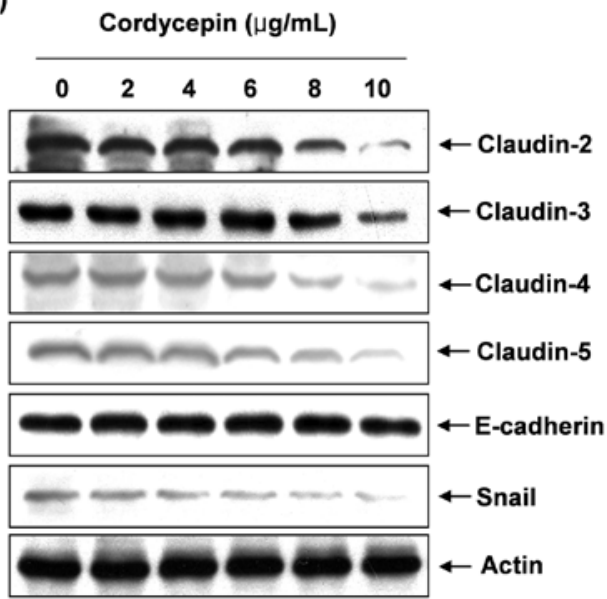

Figure 3. Effects of cordycepin on expression of claudins, E-cadherin, and snail in LNCaP cells. (A) Cells were treated with the indicated concentrations of cordycepin for $48 \mathrm{~h}$. Total RNA was isolated and reverse-transcribed using the indicated primers. Resulting cDNAs were then subjected to PCR and the reaction products were subjected to electrophoresis in a $1 \%$ agarose gel and visualized by EtBr staining. GAPDH was used as an internal control. (B) Cells grown under the same conditions as (A) were sampled, lysed, and $50 \mu \mathrm{g}$ of proteins were separated by electrophoresis on SDS-polyacrylamide gels. Western blotting was then performed using the indicated antibodies, and an ECL detection system. Actin was used as an internal control.

A)

Cordycepin $(\mu \mathrm{g} / \mathrm{mL})$

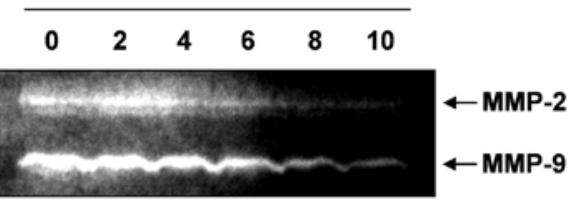

B)

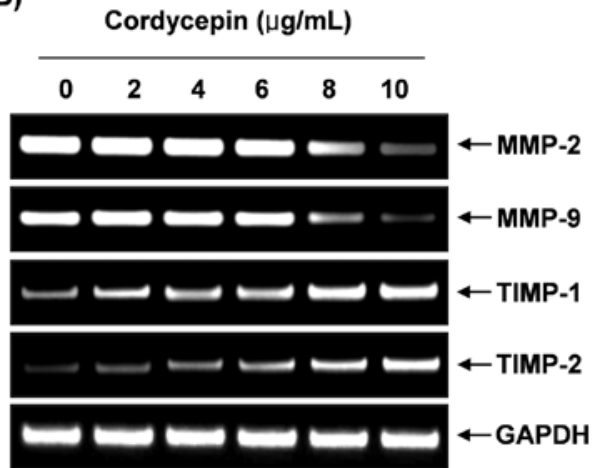

C)

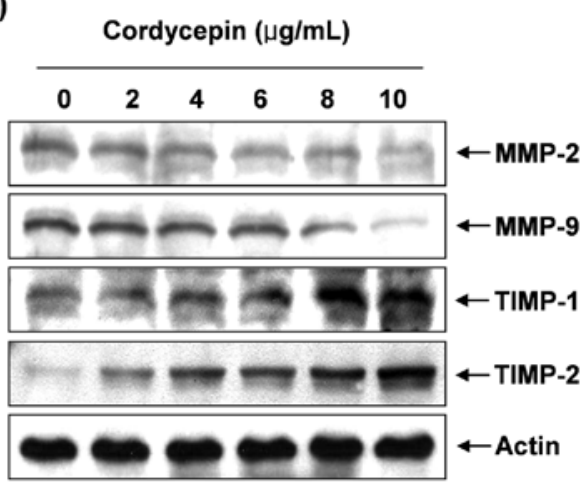

Figure 4. Inhibition of MMP expression and their activities, and induction of TIMPs expression by cordycepin in LNCaP cells. (A) Cells were treated with the indicated concentrations of cordycepin for $48 \mathrm{~h}$. The medium was collected, and the activities of MMP-2 and -9 were measured by zymography. (B) After incubation with cordycepin under the same conditions as those of (A), total RNA was isolated and reverse-transcribed. Resulting cDNAs were then subjected to PCR. The reaction products were subjected to electrophoresis in a $1 \%$ agarose gel and visualized by EtBr staining. GAPDH was used as an internal control (C) Cells grown under the same conditions as (A) were sampled, lysed, and $50 \mu \mathrm{g}$ of proteins were separated by electrophoresis on SDS-polyacrylamide gels. Western blotting was then performed using the indicated antibodies, and an ECL detection system. Actin was used as an internal control.

expression as well as anti-invasiveness were significantly suppressed by the Akt inhibitor (LY294002), which indicates that cordycepin-induced inhibition of invasion is mediated through the suppression of the PI3K/Akt pathway.

\section{Discussion}

Cancer cell migration and invasion are critical steps during metastasis; therefore, inhibition of cell migration and invasion are important mechanisms for consideration in the development of anti-metastatic drugs. In the present study, it was investigated whether or not cordycepin, a major active component of C. militaris, has potent anti-metastatic activities in LNCaP human prostate carcinoma cells. We found that cordycepin inhibited cell motility and invasive activity by the tightening of TJs and decreasing MMP activity, which is associated with inhibition of the PI3K/Akt pathway.

Recently, a frequent association of the development of human cancer with failure of epithelial cells to form TJs and to establish correct apicobasal polarity has become increasingly 
A)

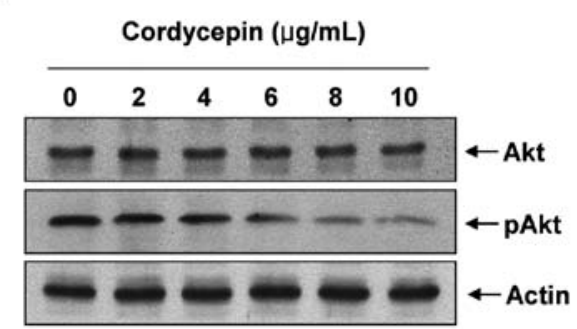

B)

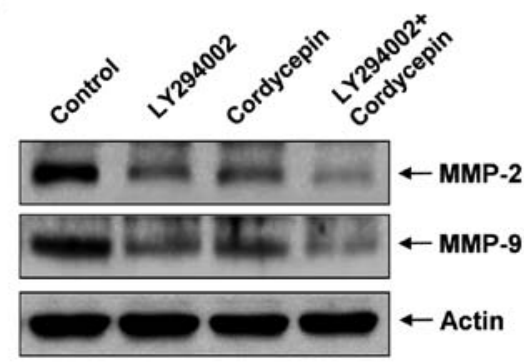

C)

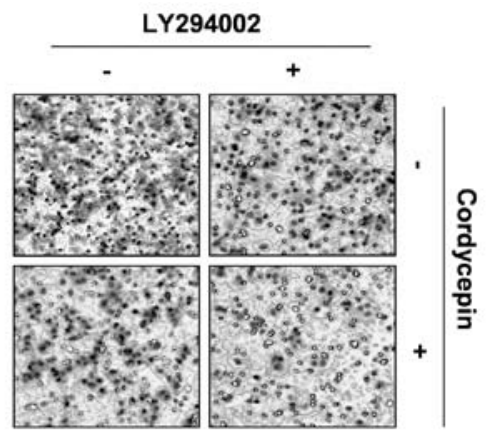

D)

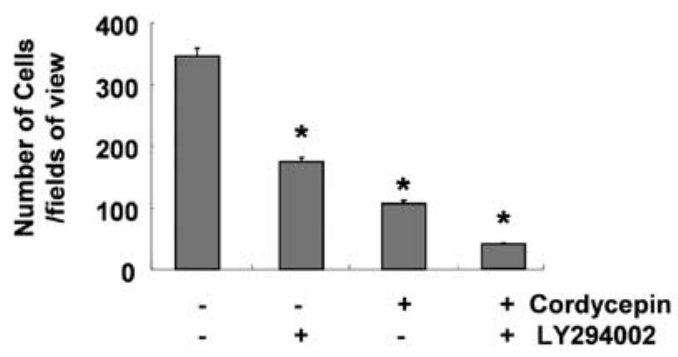

Figure 5. Increase in cordycepin-induced anti-invasiveness by inhibition of PI3K/Akt signaling in LNCaP cells. (A and B) Cells were treated with the indicated concentrations of cordycepin for $48 \mathrm{~h}$ (A) or the PI3K/Akt inhibitor, LY294002 $(10 \mu \mathrm{M})$, was added to LNCaP cells and incubated for $2 \mathrm{~h}$ before treatment with $10 \mu \mathrm{g} / \mathrm{ml}$ cordycepin for $48 \mathrm{~h}$ (B). The cells were lysed and cellular proteins were separated by SDS-polyacrylamide gels and transferred onto nitrocellulose membranes. The membranes were probed with anti-Akt, anti-p-Akt, anti-MMP-2 and anti-MMP-9 antibodies. Proteins were visualized using the ECL detection system. Actin was used as an internal control. (C and D) Cells treated with LY294002 $(10 \mu \mathrm{M})$ for $2 \mathrm{~h}$ before being challenged with $10 \mu \mathrm{g} / \mathrm{ml}$ cordycepin for $6 \mathrm{~h}$ were plated onto the apical side of matrigel coated filters in serum-free medium containing either vehicle or cordycepin. Medium containing $20 \%$ FBS was placed in the basolateral chamber to act as a chemoattractant. After $48 \mathrm{~h}$, cells on the apical side were wiped off using a Q-tip. Next, cells on the bottom of the filter were stained using hematoxylin and eosin $\mathrm{Y}(\mathrm{C})$, and then counted (D). Data are shown as the mean of triplicate samples and represent invasive cell numbers, compared with those of control cells. ${ }^{*} \mathrm{p}<0.05$ versus untreated control.

clear $(1,2)$. These data suggest that changes in permeability and loss of cell polarity are hallmarks of epithelial cell tumorigenesis. TJs are critical structures in the maintenance of these functions in epithelial cells, and their modulation is observed in a number of epithelial cancers, indicating that disruption of TJs and dysregulation of their constituent proteins play critical roles in cancer progression, invasion, and metastasis $(2,4)$. Several previous studies have shown that many anticancer agents are inhibitory to motility and invasiveness, and that they act by enhancement of transepithelial paracellular permeability $(1,35-38)$. Our results show that treatment with non-toxic concentrations of cordycepin increases the TER of LNCaP cells in a dose-dependent manner, which is associated with inhibition of cell motility and invasiveness (Figs. 1 and 2). These results imply that the inhibitory effects of cordycepin on migration and invasion of $\mathrm{LNCaP}$ cells are not due to its cytotoxic effect and indicates that cordycepin may prevent or reverse leakage of TJs. Since, leakage of TJs is tightly associated with the process of cancer metastasis, tightening of TJs may be expected to have anticancer activity. Thus, the antiinvasive activity of cordycepin may be due, in part, to its ability to enhance TJ activity.

Among the many components of TJs, members of the claudin family, which are transmembrane proteins with extracellular domains, interact with other claudins associated with adjacent cells in the regulation of paracellular permeability $(5,7,15)$. Emerging evidence indicates that disruption of TJs, with concomitant dysregulation of TJ proteins, is an early event in cancer cell invasion and metastasis (8-10). In particular, overexpression of claudin- 3 and -4 has been demonstrated in several tumors, including breast and ovarian cancers (36). Conversely, 'knockdown' of these two claudins inhibited the invasiveness of cancer cells (37). We also recently showed that claudin-1 plays a causal role in acquisition of invasive capacity in human liver cells, which is associated with increased expression of MMP-2. However, small interfering RNA targeting of claudin-1 in invasive hepatocellular carcinoma cells completely inhibited cell invasion (38). These observations indicate that claudin proteins may prove to be useful biomarkers for detection and diagnosis of certain cancers. In the present study, we showed that cordycepin significantly inhibited expression of claudin family proteins (claudin-2, -3 , -4 and -5 ) in a concentration-dependent fashion (Fig. 3). In addition, E-cadherin, an adherens junction protein and a typeI transmembrane glycoprotein (32), is also known to regulate TJ formation (39). Moreover, the EMT regulator, snail, can also lead to decreased cell-cell adhesion and increased cell invasiveness in conjunction with the loss of E-cadherin expression, in many types of human cancers $(29,40)$. In our results, the levels of snail, but not E-cadherin, were gradually downregulated by cordycepin treatment. Although we need to validate this study, we tentatively suggest that cordycepin, through effects on the expression of snail, may mediate anti-metastasis and anti-invasiveness in $\mathrm{LNCaP}$ cells. 
MMPs are important proteolytic enzymes in organ development and tissue regeneration; however, they also play important roles in cancer cell invasion. In particular, MMP-2 and -9 play important roles in tumor invasion and angiogenesis; therefore, tumor metastasis can be inhibited by blocking MMP synthesis and activity $(13,14)$. The activity of MMPs is tightly controlled by transcriptional activation, by a complex proteolytic activation cascade, and by an endogenous system of TIMPs. TIMPs inhibit MMPs by formation of stoichiometric complexes for regulation of matrix turnover $(15,16)$. Therefore, we next determined whether the anti-invasive effects of cordycepin were associated with modulation of TIMP and MMP expression or activity. Our results indicate that cordycepin markedly inhibits the expression of MMP-2 and MMP-9 mRNA and protein levels, as well as their enzymatic activities. On the contrary, the transcriptional and translational levels of both TIMP-1 and TIMP-2 showed concentration-dependent upregulation in response to cordycepin treatment. The present data demonstrate that cordycepin-induced inhibition of cell motility and invasion is related to downregulation of MMP-2 and -9 activities through elevation of TIMPs expression. Therefore, our results suggest that cordycepin induces an increase in the TIMPs/MMPs ratio as a key factor in regulation of the antimetastatic process, which subsequently blocks degradation of the ECM and leads to inhibition of cell invasion.

Although the PI3K/Akt signal pathways play a critical role in regulating cell survival and death in many physiological and pathological settings, numerous studies have demonstrated that expression of TJs and MMPs are critically mediated by the PI3K/Akt pathways, suggesting that these pathways also play an important role in tumor metastasis $(33,34,41)$. Thus, we confirmed the involvement of the PI3K/Akt pathway in cordycepin-induced anti-invasive activity using LY294002, a representative PI3K/Akt inhibitor. As indicated in Fig. 5, phosphorylated-Akt levels were decreased by cordycepin treatment in a concentration-dependent manner, and combined exposure with LY294002 made the cells more sensitive to cordycepin-induced downregulation of MMPs and inhibition of cell invasion. Therefore, we suggest that cordycepin inhibition of cell invasion of LNCaP cells might partly occur by suppressing the PI3K/Akt pathway.

In conclusion, the results of our studies provide mechanistic evidence that cordycepin inhibits cell motility and invasion of LNCaP human prostate carcinoma cells by increasing TJ activity and downregulation of MMP activity through Akt dephosphorylation. However, additional in vivo studies are needed to establish the role of cordycepin as an anti-metastatic agent for treatment of cancer.

\section{Acknowledgements}

Cheng-Yun Jin is the recipient of postdoctoral fellowship from the Ministry of Education, Science and Technology through the Brain Korea 21 Project. This research was supported by Technology Development Program for Agriculture and Forestry (610003-03-1-SU000), Ministry for Food, Agriculture, Forestry and Fisheries, and Basic Science Research Program through the National Research Foundation of Korea (NRF) funded by the Ministry of Education, Science, and Technology (2010-0001730).

\section{References}

1. Soler AP, Miller RD, Laughlin KV, Carp NZ, Klurfeld DM and Mullin JM: Increased tight junctional permeability is associated with the development of colon cancer. Carcinogenesis 20: 1425-1431, 1999.

2. Schneeberger EE and Lynch RD: The tight junction: a multifunctional complex. Am J Physiol Cell Physiol 286: C1213-C1228, 2004.

3. Furuse M, Furuse K, Sasaki H and Tsukita S: Conversion of zonulae occludentes from tight to leaky strand type by introducing claudin-2 into Madin-Darby canine kidney I cells. J Cell Biol 153: 263-272, 2001.

4. Rubenwolf P and Southgate J: Permeability of differentiated human urothelium in vitro. Methods Mol Biol 763: 207-222, 2011.

5. Morin PJ: Claudin proteins in human cancer: promising new targets for diagnosis and therapy. Cancer Res 65: 9603-9606, 2005.

6. Utech M, Brüwer M and Nusrat A: Tight junctions and cell-cell interactions. Methods Mol Biol 341: 185-195, 2006.

7. Angelow S and Yu AS: Claudins and paracellular transport: an update. Curr Opin Nephrol Hypertens 16: 459-464, 2007.

8. Krause G, Winkler L, Mueller SL, Haseloff RF, Piontek J and Blasig IE: Structure and function of claudins. Biochim Biophys Acta 1778: 631-645, 2008.

9. Singh AB, Sharma A and Dhawan P: Claudin family of proteins and cancer: an overview. J Oncol 2010: 541957, 2010.

10. Turksen K and Troy TC: Junctions gone bad: claudins and loss of the barrier in cancer. Biochim Biophys Acta 1816: 73-79, 2011.

11. John A and Tuszynski G: The role of matrix metalloproteinases in tumor angiogenesis and tumor metastasis. Pathol Oncol Res 7: 14-23, 2001.

12. Vihinen P, Ala-aho R and Kähäri VM: Matrix metalloproteinases as therapeutic targets in cancer. Curr Cancer Drug Targets 5: 203-220, 2005.

13. Gibbs DF, Warner RL, Weiss SJ, Johnson KJ and Varani J: Characterization of matrix metalloproteinases produced by rat alveolar macrophages. Am J Respir Cell Mol Biol 20: 1136-1144, 1999.

14. Mook OR, Frederiks WM and Van Noorden CJ: The role of gelatinases in colorectal cancer progression and metastasis. Biochim Biophys Acta 1705: 69-89, 2004.

15. Uzui H, Harpf A, Liu M, Doherty TM, Shukla A and Chai N: Increased expression of membrane type 3-matrix metalloproteinase in human atherosclerotic plaque: role of activated macrophages and inflammatory cytokines. Circulation 106: 3024-3030, 2002.

16. Lambert E, Dasse E, Haye B and Petitfrere E: TIMPs as multifacial proteins. Crit Rev Oncol Hematol 49: 187-198, 2004.

17. Cunningham KG, Manson W, Spring FS and Hutchinson SA: Cordycepin, a metabolic product isolated from cultures of Cordyceps militaris (Linn.) Link. Nature 166: 949, 1950.

18. Paterson RR: Cordyceps: a traditional Chinese medicine and another fungal therapeutic biofactory? Phytochemistry 69: 1469-1495, 2008.

19. Müller WE, Weiler BE, Charubala R, Pfleiderer W, Leserman L, Sobol RW, Suhadolnik RJ and Schröder HC: Cordycepin analogues of 2',5'-oligoadenylate inhibit human immunodeficiency virus infection via inhibition of reverse transcriptase. Biochemistry 30: 2027-2033, 1991

20. Job D, Durand R, Job C and Teissere M: Complex RNA chain elongation kinetics by wheat germ RNA polymerase II. Nucleic Acids Res 12: 3303-3319, 1984.

21. Wu WC, Hsiao JR, Lian YY, Lin CY and Huang BM: The apoptotic effect of cordycepin on human OEC-M1 oral cancer cell line. Cancer Chemother Pharmacol 60: 103-111, 2007.

22. Chen LS, Stellrecht CM and Gandhi V: RNA-directed agent, cordycepin, induces cell death in multiple myeloma cells. Br J Haematol 140: 682-691, 2008.

23. Thomadaki H, Tsiapalis CM and Scorilas A: The effect of the polyadenylation inhibitor cordycepin on human Molt-4 and Daudi leukaemia and lymphoma cell lines. Cancer Chemother Pharmacol 61: 703-711, 2008

24. Chen Y, Chen YC, Lin YT, Huang SH and Wang SM: Cordycepin induces apoptosis of CGTH W-2 thyroid carcinoma cells through the calcium-calpain-caspase 7-PARP pathway. J Agric Food Chem 58: 11645-11652, 2010 
25. Jeong JW, Jin CY, Park C, Hong SH, Kim GY, Jeong YK, Lee JD, Yoo YH and Choi YH: Induction of apoptosis by cordycepin via reactive oxygen species generation in human leukemia cells. Toxicol In Vitro 25: 817-824, 2011.

26. Zhu W, Fu A, Hu J, Wang T, Luo Y, Peng M, Ma Y, Wei Y and Chen L: 5-Formylhonokiol exerts anti-angiogenesis activity via inactivating the ERK signaling pathway. Exp Mol Med 43: 146-152, 2011.

27. Grant-Tschudy KS and Wira CR: Effect of oestradiol on mouse uterine epithelial cell tumour necrosis factor-alpha release is mediated through uterine stromal cells. Immunology 115: 99-107, 2005.

28. Song HY, Ju SM, Goh AR, Kwon DJ, Choi SY and Park J: Suppression of TNF-alpha-induced MMP-9 expression by a cellpermeable superoxide dismutase in keratinocytes. BMB Rep 44: 462-467, 2011

29. Yokoyama K, Kamata N, Hayashi E, Hoteiya T, Ueda N, Fujimoto R and Nagayama M: Reverse correlation of E-cadherin and snail expression in oral squamous cell carcinoma cells in vitro. Oral Oncol 37: 65-71, 2001

30. Usami Y, Satake S, Nakayama F, Matsumoto M, Ohnuma K, Komori T, Semba S, Ito A and Yokozaki H: Snail-associated epithelial-mesenchymal transition promotes oesophageal squamous cell carcinoma motility and progression. J Pathol 215: 330-339, 2008

31. Nelson WJ and Nusse R: Convergence of Wnt, $\beta$-catenin, and cadherin pathways. Science 303: 1483-1487, 2004.

32. McLachlan RW and Yap AS: Not so simple: the complexity of phosphotyrosine signaling at cadherin adhesive contacts. J Mol Med 85: 545-554, 2007.

33. Shukla S, Maclennan GT, Hartman DJ, Fu P, Resnick MI and Gupta S: Activation of PI3K-Akt signaling pathway promotes prostate cancer cell invasion. Int J Cancer 121: 1424-1432, 2007.
34. Li N and Neu J: Glutamine deprivation alters intestinal tight junctions via a PI3-K/Akt mediated pathway in Caco-2 cells. J Nutr 139: 710-714, 2009.

35. Gitter AH, Bendfeldt K, Schmitz H, Schulzke JD, Bentzel CJ and Fromm M: Epithelial barrier defects in HT-29/B6 colonic cell monolayers induced by tumor necrosis factor- $\alpha$. Ann NY Acad Sci 915: 193-203, 2000.

36. Rangel LB, Agarwal R, D'Souza T, Pizer ES, Alò PL, Lancaster WD, Gregoire L, Schwartz DR, Cho KR and Morin PJ: Tight junction proteins claudin- 3 and claudin- 4 are frequently overexpressed in ovarian cancer but not in ovarian cystadenomas. Clin Cancer Res 9: 2567-2575, 2003.

37. Agarwal R, D'Souza T and Morin PJ: Claudin-3 and claudin-4 expression in ovarian epithelial cells enhances invasion and is associated with increased matrix metalloproteinase-2 activity. Cancer Res 65: 7378-7385, 2005.

38. Yoon CH, Kim MJ, Park MJ, Park IC, Hwang SG, An S, Choi YH, Yoon G and Lee SJ: Claudin-1 acts through c-Abl-protein kinase Cdelta (PKCס) signaling and has a causal role in the acquisition of invasive capacity in human liver cells. J Biol Chem 285: 226-233, 2010.

39. Van Itallie CM and Anderson JM: Claudins and epithelial paracellular transport. Annu Rev Physiol 68: 403-429, 2006.

40. Grotegut S, von Schweinitz D, Christofori G and Lehembre F: Hepatocyte growth factor induces cell scattering through MAPK/ Egr-1-mediated upregulation of Snail. EMBO J 25: 3534-3545, 2006.

41. Samuels Y and Ericson K: Oncogenic PI3K and its role in cancer. Curr Opin Oncol 18: 77-82, 2006. 